\title{
Prevalence and Risk Factors Associated With Chronic Kidney Disease Among Patients Presenting at a Haemodialysis Unit in Dodoma, Tanzania
}

\author{
Alfred J Meremo, ${ }^{a, b}$ Matobogolo B Masalu, ${ }^{a, b}$ Issa Sabi, ${ }^{c}$ David P Ngilangwa, ${ }^{d}$ Janet Kapinga, ${ }^{b}$ \\ Rehema Tagalile, ${ }^{b}$ Mariam J Munyogwa, ${ }^{a}$ Masumbuko Y Mwashambwa ${ }^{a, b}$
}

a School of Medicine and Dentistry, College of Health Sciences, The University of Dodoma, Dodoma, Tanzania; ${ }^{b}$ Haemodialysis Unit, The University of Dodoma, Dodoma, Tanzania; ' National Institute for Medical Research, Mbeya Medical Research Centre, Mbeya, Tanzania; ${ }^{d}$ Amref Health Africa, Dar es Salaam, Tanzania. Correspondence to Alfred J Meremo (meremoal@gmail.com).

\begin{abstract}
Background: Chronic kidney disease (CKD) is a major public health problem worldwide, due to its epidemic proportions and the associated cardiovascular morbidity and mortality. However, data on the burden of CKD among patients attending hospitals in Tanzania are still limited. The aim of this study was to determine the prevalence and risk factors associated with CKD among patients presenting at the University of Dodoma (UDOM) haemodialysis unit in Tanzania.

Methods: In this retrospective study, we reviewed data of 1,395 patients who presented at the UDOM haemodialysis unit from January 2013 to June 2015. Data were descriptively and inferentially analysed using Stata version 11.0.

Results: From January 2013 to June 2015, a total of 1,395 patients presented at the UDOM haemodialysis unit with history of kidney disease. Of these patients, 1244 (89.2\%) enrolled into this study, 651 (52.3\%) of them were female. Almost two-thirds ( $n=792,63.7 \%$ ) of the patients were found to have CKD, 59.1\% with an estimated glomerular filtration rate of $<60 \mathrm{~mL} / \mathrm{min} / 1.73 \mathrm{~m}^{2}$. Among those who had CKD, $347(43.8 \%)$ had hypertension, $241(30.4 \%)$ had diabetic mellitus, 79 (10.0\%) had chronic glomerulonephritis, 70 (8.8\%) had hypertension and diabetes mellitus, $38(4.8 \%)$ had $\mathrm{HIV} / \mathrm{AIDS}$, and $17(2.1 \%)$ had hepatitis B. The median serum creatinine level was $222 \mu \mathrm{mol} / \mathrm{L}$ (interquartile range [IQR] 126 to 317), urea level was $14.5 \mathrm{mmol} / \mathrm{L}$ (IQR 5 to 24), hemoglobin was $11.0 \mathrm{~g} / \mathrm{dL}$ (IQR 6.2 to 15.7 ), and body mass index was $27.1 \mathrm{~kg} / \mathrm{m}^{2}$ (IQR 17.3 to 36.8 ). Obesity, diabetes mellitus, and systolic hypertension were associated with developing CKD $(P<.001)$. A total of 116 patients received haemodialysis during the study period.

Conclusion: CKD was common among patients presenting in our hospital and is associated with high cardiovascular risk. To that end, patients should be thoroughly evaluated to identify and correct causes of their kidney disease, and efforts should be put in place for early detection and screening as well as advocacy on risk factors for CKD development in Tanzania.
\end{abstract}

\section{INTRODUCTION}

C hronic Kidney Disease (CKD) is found in 10\% of the global population, and is considered a major public health problem worldwide, due to its epidemic proportions and its association with high cardiovascular risk. ${ }^{1}$ CKD is defined as abnormalities of kidney structure or function present or decreased estimate glomerular filtration rate (eGFR) for more than 3 months with implications for health, and classified into 5 stages according to the eGFR. ${ }^{2-5}$ The current recommendation is to use serum creatinine concentration to estimate the eGFR and transform it using the CKD Epidemiology Collaboration (CKD-EPI) equation. ${ }^{5}$

CKD is associated with age-related renal function decline accelerated in hypertension, diabetes, obesity and primary renal disorders. ${ }^{6}$ Although cardiovascular disease (CVD) is the primary cause of morbidity and mortality, CKD is regarded as an accelerator of CVD risk and an independent risk factor for CVD events. ${ }^{7}$ Also CKD severely affects patients' health, lifestyle and wellbeing, and quality of life ${ }^{8}$; it is at least 3 to 4 times more 
frequent in Africa than in developed countries. ${ }^{9}$ Despite high demand, very few patients in some African countries receive renal replacement therapy, mainly because of resource constraints. $^{10}$

A study conducted between 2007 and 2010 in United States found that an estimated $14.0 \%$ of the U.S adult population had CKD. ${ }^{11}$ Although the causes vary, diabetes was the most common cause of CKD in the United States and is steadily increasing as the cause worldwide. ${ }^{12}$ In a study conducted in a hospital in Singapore, researchers found that $87.7 \%$ of the patients had moderate to severe CKD (stage 3 and above); the majority of the patients had dyslipidemia $(92.8 \%)$, hypertension $(89.3 \%)$ and diabetes mellitus $(64.6 \%) .{ }^{13}$ In a study conducted in South Africa's black population, researchers found that primary hypertension occurred in $25.0 \%$ of the study population and was considered the cause of stage 5 CKD in $40.0 \%$ to $60.0 \%$ of these patients. ${ }^{2}$ In another study conducted in South Africa, the authors also reported hypertension as the leading cause in the adult population and the cause of chronic kidney failure in $21.0 \%$ of patients on renal replacement therapy registry. ${ }^{9}$ The prevalence of diabetic nephropathy is estimated to be $14.0 \%$ to $16.0 \%$ in South Africa, $23.8 \%$ in Zambia, $12.4 \%$ in Egypt, $9 \%$ in Sudan, and $6.1 \%$ in Ethiopia. ${ }^{9}$ In a study conducted in Nigeria, the overall prevalence of CKD was $18.8 \%$. The researchers attributed the disease to hypertension $(30.0 \%)$, diabetes mellitus $(3.7 \%)$, obesity $(14.6 \%)$, and haematuria $(3.1 \%$.), with age, female gender, systolic blood pressure, and diabetes mellitus as predictors of CKD. ${ }^{14}$

In a study of outpatients in North Western Tanzania, an alarmingly high prevalence $(87.3 \%)$ of CKD was identified among adult patients attending diabetes mellitus clinic. ${ }^{15}$ In a community-based study conducted in Northern Tanzania, the overall prevalence of CKD was found to be 7\%; and, of these patients, $19.3 \%$ had hypertension alone, $14.0 \%$ had both diabetes and hypertension, $7.0 \%$ had diabetes alone, $7.0 \%$ had HIV alone, and 3.5\% had both HIV and hypertension. Nearly half $(49.2 \%)$ of the cases of CKD were not associated with any of the measured risk factors of hypertension, diabetes, or HIV. ${ }^{16}$ Another hospital study conducted in North Western Tanzania, reported that hypertension-related diseases were the most common cause of hospital admission and CKD, and accounted for most deaths. ${ }^{17}$

While CKD is associated with high mortality and morbidity, limited data is available on the burden of CKD among patients attending hospitals in Tanzania, and, to date, the country has no national registry for CKD. Very few studies on prevalence of CKD have been reported in Tanzania, those that have been conducted have focused on patients either attending diabetic clinics or seeking care in communities. ${ }^{15-17}$ The aim of this study was to determine the prevalence and risk factors associated with CKD among patients presenting at the University of Dodoma (UDOM) haemodialysis unit in Dodoma, Tanzania.

\section{METHODS}

\section{Study Design, Population, and Settings}

Data for this retrospective study data were collected from patients who presented at the UDOM haemodialysis unit from January 2013 to June 2015. The UDOM hospital started its operations in 2007, when the university was officially launched, with the main aim of providing health-care services to the UDOM staff and students as well as the community of Dodoma. The hospital serves about 120,000 people, has a bed capacity of 100, and has specialist clinics conducted and run by medical specialists from the UDOM College of Health Sciences. In January 2013, the UDOM hospital launched its haemodialysis unit. The unit serves as a referral centre for the Singida, Morogoro, Iringa, Manyara, and Tabora regions, and for other regional referral hospitals in the central and other neighbouring zones, serving a total population of 20 million people.

All patients who required haemodialysis were treated at the unit, and all patients who presented at the haemodialysis unit but had no indications for haemodialysis were scheduled for routine medical follow up and continuous medical care.

\section{Data Collection and Laboratory Procedures}

Patient medical record files of the 1,395 patients who presented at the UDOM haemodialysis unit from January 2013 to June 2015 were reviewed. Study data were obtained from handwritten medical records and then cross-checked with the electronic records. Any discrepancies were reviewed and verified to ensure the validity of data. The data were carefully reviewed and all patients with incomplete records were excluded. Information on patient sociodemographics, clinical characteristics, and relevant laboratory investigations were extracted. The study team reviewed information about age, gender, marital status, weight in kilograms, height in centimetres, clinical signs (oedema, anuria, hypertension), and laboratory dataincluding urinalysis, hepatitis panel, full blood picture, urea, creatinine, electrolytes, random blood glucose, and HIV test results-were recorded.

Body mass index (BMI) was calculated using the National Health Services (United Kingdom) BMI calculator, an eGFR was calculated using the CKD-EPI equation, and bedside isotope-dilution mass spectrometry-traceable Schwartz GFR calculator for children was used to stage patients.

Acute kidney injury was defined as an acute deterioration in renal excretory function, with a serum urea $>10 \mathrm{mmol} / \mathrm{L}$ and/or a rise in serum creatinine (Scr) by $\geq 0.3 \mathrm{mg} / \mathrm{dL}$, or a percentage increase in Scr of $\geq 50 \%$ from baseline using the Acute Kidney Injury Network criteria. End stage renal disease was defined as progressive CKD with $\mathrm{eGFR} \leq 15 \mathrm{~mL} / \mathrm{min} / 1.73 \mathrm{~m}^{2}$ with or without other indications for haemodialysis. Outcome measures were CKD and its associated risk factors. 


\section{Data Analysis}

The de-identified data collected were entered into a computer using EpiData version 3.1 (CDC, Atlanta, USA) and analysed using Stata version 11.0 (StataCorp LLC, College Station, Texas, USA). Data were summarized as proportions and frequency tables for categorical variables. Depending on variable distribution, either mean with standard deviation or median with interquartile range were used to summarize continuous data. The correlation between the development of CKD and different patient parameters was determined by performing logistic regression analyses. Odds ratios (OR) were calculated to estimate the percentage change in risk of CKD development, and parameters with $P$ values $<.05$ were considered statistically significant.

\section{Ethical Considerations}

The study was approved by the UDOM research and publications ethics review board. Waiver of consent was approved by the committees as this retrospective study analysed only de-identified data.

\section{RESULTS}

\section{Demographic and Other Characteristics of the Study Population}

A total of 1,395 patients presented at the UDOM haemodialysis unit from January 2013 to June 2015. Of these patients, $151(10.8 \%)$ were excluded from this study due to incomplete records, and the remaining 1,244 (89.2\%) patients were enrolled in this study. The median age of the study population was 36 years (interquartile range [IQR] 6 to 88), over half $(n=651,52.3 \%)$ were female, more than half $(n=704$, $56.6 \%)$ were classified as obese, and about a third $(n=434$, $34.9 \%$ ) reported having a history of smoking. A small percentage of the study population was living with HIV $(n=57$, $4.6 \%)$ or hepatitis B $(n=26,2.1 \%)$. Of the 1,244 patients enrolled, $792(63.7 \%)$ were found to have CKD, 59.1\% with an eGFR of $<60 \mathrm{~mL} / \mathrm{min} / 1.73 \mathrm{~m}^{2}$ and 452 (36.3\%) had no CKD after screening. A total of 116 patients received haemodialysis during study period, $32(27.6 \%)$ of whom were found to have acute kidney injury (Table 1).

\section{Causes of CKD Among Patients Who Presented at the Haemodialysis Unit}

Of the 792 patients found to have CKD, 347 (43.8\%) had hypertension, 241 (30.4\%) had diabetes mellitus, $79(10.0 \%)$ had chronic glomerulonephritis, and $70(8.8 \%)$ had both hypertension and diabetes mellitus, while $38(4.8 \%)$ and $17(2.1 \%)$ were associated with HIV/AIDS and hepatitis $\mathrm{B}$, respectively (Table 2).

\section{Risk Factors Associated With CKD Among Patients Who Presented at the Haemodialysis Unit}

A total of 15 potential risk factors were identified after performing univariate logistic regression analyses. Backward
TABLE 1. Baseline Characteristics of Patients Who Presented at the University of Dodoma Haemodialysis Unit

Characteristic

Proportion (\%) or Median [IQR]

Sex

Male

593 (47.7)

Female

651 (52.3)

Age, in years

36 [6-88]

Marital status

Never married

357 (28.7)

Married

479 (38.5)

Divorced

215 (17.3)

Widow

$193(15.5)$

Smoking status (ever)

No

$810(65.1)$

Yes

434 (34.9)

Obesity (BMI) kg/m²

27.1 [17.3-36.8]

Haemoglobin (g/dL)

11.0 [6.2-15.7]

Serum creatinine level ( $\mu \mathrm{mol} / \mathrm{L})$

222 [126-317]

Urea level (mmol/L)

$14.5[5-24]$

HIV status

Positive

57 (4.5)

Negative

1187 (95.4)

Hepatitis

Positive

$26(2.1)$

Negative

$1218(97.9)$

Chronic kidney disease

No

452 (36.3)

Yes

$792(63.7)$

Classification of stage of chronic kidney disease $(n=792)$

Stage one

32 (4.0)

Stage two

$292(36.9)$

Stage three

220 (27.7)

Stage four

$164(20.7)$

Stage five

$84(10.6)$

Abbreviations: $B M I$, body mass index; $I Q R$, interquartile range. 


\begin{tabular}{lc}
\hline TABLE 2. Causes of Chronic Kidney Disease Among \\
Patients Who Presented at the Haemodialysis Unit \\
\hline Medical Condition & $\begin{array}{c}\text { Patients with CKD } \\
\mathbf{n}(\%)\end{array}$ \\
\hline Hypertension & $347(43.8 \%)$ \\
Diabetes mellitus & $241(30.4 \%)$ \\
Chronic glomerulonephritis & $79(10.0 \%)$ \\
Both hypertension and diabetes mellitus & $70(8.8 \%)$ \\
HIV/AIDS & $38(4.8 \%)$ \\
Hepatitis & $17(2.1 \%)$ \\
\hline
\end{tabular}

Abbreviation: CKD, chronic kidney disease.

elimination reduced this to 4 parameters. The potential predictors identified were gender, age, obesity, history of smoking, and causes of CKD. Gender, age, and smoking were found to be significant in univariate logistic regression analyses. However, this significance was lost after multivariate logistic regression analyses (Table 3 ).

Obesity (BMI $\geq 30$ ) was predictive of CKD development (OR 8.7; 95\% confidence interval [CI], 3.5 to $15.9 ; P<.001$ ). In addition, the multivariate adjusted odds of CKD development were 9.2 times higher for a patient with diabetes mellitus (OR 9.23; 95\% CI, 4.64 to 19.57; $P<.001)$. Patients with systolic hypertension (OR 7.5; 95\% CI, 3.94 to 1 1.68; $P<.001$ ) also had higher odds of developing CKD.

\section{DISCUSSION}

This study evaluated the prevalence and risk factors associated with CKD at the UDOM hospital. A total of $792(63.7 \%)$ patients enrolled in the study were found to have CKD, of whom $59.1 \%$ had an eGFR of $<60 \mathrm{~mL} / \mathrm{min} /$ $1.73 \mathrm{~m}^{2}$. These findings are lower than an earlier study conducted by Janmohamed et al in North Western Tanzania, that showed the prevalence of CKD to be $80.0 \%$ among adults with diabetes mellitus, with nearly $25.0 \%$ having an eGFR of $<60 \mathrm{~mL} / \mathrm{min} / 1.73 \mathrm{~m}^{2} .{ }^{15}$ These findings are also contrary with a community-based study conducted in Northern Tanzania, where the overall prevalence of CKD was found to be $7.0 \% .{ }^{16}$ The vast differences in the findings could be attributed to the difference in study populations.

In a hospital study conducted in Singapore, researchers found that $87.7 \%$ of patients had moderate to severe $\mathrm{CKD}^{13}$; while in another hospital study conducted in Nigeria, found the overall prevalence to be $18.8 \% .{ }^{14}$ CKD was at least 3 to 4 times more frequent in Africa than in developed countries. ${ }^{9,11}$ In a country like Tanzania, where

\begin{tabular}{|c|c|c|}
\hline Parameters & $\begin{array}{l}\text { Adjusted OR (95\% } \\
\text { confidence interval) }\end{array}$ & Pvalue \\
\hline Gender & & .516 \\
\hline Male & 1.00 & \\
\hline Female & $1.3(1.1-1.8)$ & \\
\hline Age & & .135 \\
\hline$<50$ years & 1.00 & \\
\hline$\geq 50$ years & $1.8(0.9-3.7)$ & \\
\hline Smoking status (ever) & & .763 \\
\hline No & 1.00 & \\
\hline Yes & $2.6(1.6-4.3)$ & \\
\hline Obesity & & $<.001$ \\
\hline$<30$ & 1.00 & \\
\hline$\geq 30$ & $8.7(3.5-15.9)$ & \\
\hline \multicolumn{3}{|l|}{ Causes of CKD } \\
\hline Hypertension (systolic) & $7.5(3.94-11.68)$ & $<.001$ \\
\hline Diabetes mellitus & $9.23(4.64-19.57)$ & $<.001$ \\
\hline
\end{tabular}

there is no registry or advocacy for CKD prevention or early detection of kidney diseases, more effort is needed to fight the growing epidemic of noncommunicable diseases.

Of all the patients in our study who had CKD, $347(43.8 \%)$ had hypertension, 241 (30.4\%) had diabetic mellitus, $79(10.0 \%)$ had chronic glomerulonephritis, and $70(8.8 \%)$ had both hypertension and diabetes mellitus. Similar findings have been reported from other studies conducted in low- and middle-income countries, whereby hypertension has been reported to be the leading cause of CKD. ${ }^{2,9,10,13,14}$ However, these findings are contrary to a community-based study conducted in Northern Tanzania that showed that nearly half $(49.2 \%)$ of the cases of CKD were not associated with any of the measured risk factors of hypertension, diabetes, or HIV. ${ }^{16}$ This discrepancy calls for more research into other causes of $\mathrm{CKD}$, including the use of local herbs and medicines, which is very rampant in this area where this study was conducted. Different findings have also been reported from the United States and other developed countries, whereby diabetes mellitus has been reported as the leading cause of CKD and is steadily increasing as the cause worldwide. ${ }^{4,11,12,18}$ 
Our study found that $704(56.6 \%)$ patients were found to be obese and $434(34.9 \%)$ patients reported having had a history of smoking. Similar findings have been reported from other studies whereby obesity and positive history of smoking were reported as risk factors for CKD. ${ }^{14,19-21}$ In this study obesity (BMI $\geq 30)$, diabetes mellitus and systolic hypertension were strongly associated with development of CKD $(P<.001)$. Similar findings have been reported from other studies. ${ }^{6,14,19-21}$

\section{Limitations and Strengths}

This study was conducted in a hospital in central part of Tanzania and, as such, the results are limited to patients in the central part of Tanzania. Despite the limited generalizability, this information could provide insight to strategies for improving the management of patients who present with CKD in hospitals. The strengths of this study were that our hospital uses both paper-based and electronic medical records, which allowed the recording and collection of patients' health related information in real time. The study data were obtained from handwritten medical records and then cross checked with the electronic records. Any discrepancies were reviewed and verified to ensure the validity of data.

\section{CONCLUSION}

CKD was common among patients presenting in our hospital and is associated with high cardiovascular risk. To that end, patients should be thoroughly evaluated to identify and correct the causes of their disease. As CKD is regarded as an accelerator of cardiovascular risks and an independent risk factor for cardiovascular events and eventually death, efforts should be put in place for early detection and screening as well as advocacy on risk factors for CKD development in Tanzania.

\begin{abstract}
Acknowledgements: Special thanks to staff working at the UDOM hospital for the services they are providing to patients and for proper keeping of data which made this study possible. Additional thanks to the members of the Department of Internal Medicine of the College of Health Sciences for their excellent technical assistance and to the UDOM management for continuous material and moral support to the hospital.
\end{abstract}

\section{REFERENCES}

1. Cepoi V, Onofriescu M, Segall L, Covic A. The prevalence of chronic kidney disease in the general population in Romania: a study on 60,000 persons. Int Urol Nephrol. 2012;44(1):213-220. CrossRef. Medline

2. Meyers AM. Significance, definition, classification and risk factors of chronic kidney disease in South Africa. S Afr Med J. 2015;105(3):233-236. CrossRef. Medline

3. Kidney Disease: Improving Global Outcomes (KDIGO) Chronic Kidney Disease Work Group. KDIGO 2012 clinical practice guideline for the evaluation and management of chronic kidney disease. Kidney Int Suppl. 2013;3:1-150. CrossRef

4. National Institute for Health and Care Excellence (NICE). Chronic Kidney Disease: Early Identification and Management of Chronic Kidney Disease in Adults in Primary and Secondary Care. Clinical Guideline [CG73]. London: NICE; 2008. http:// guidance.nice.org.uk/CG73/Guidance/pdf/English. Accessed 26 January 2018.

5. Levey AS, Stevens LA, Schmid CH, et al; CKD-EPI (Chronic Kidney Disease Epidemiology Collaboration). A new equation to estimate glomerular filtration rate. Ann Intern Med. 2009;150(9):604-612. CrossRef. Medline
6. Gansevoort RT, Correa-Rotter R, Hemmelgarn BR, et al. Chronic kidney disease and cardiovascular risk: epidemiology, mechanisms, and prevention. Lancet. 2013; 382(9889):339-352. CrossRef. Medline

7. Go AS, Chertow GM, Fan D, McCulloch CE, Hsu CY. Chronic kidney disease and the risks of death, cardiovascular events, and hospitalization. NEngl J Med. 2004; 351(13):1296-1305. CrossRef. Medline

8. Bae YH, Lee SM, Jo Jl. Aerobic training during hemodialysis improves body composition, muscle function, physical performance, and quality of life in chronic kidney disease patients. J Phys Ther Sci. 2015;27(5):1445-1449. CrossRef. Medline

9. Naicker S. End-stage renal disease in sub-Saharan Africa. Ethn Dis. 2009;19(suppl 1):S1-13-5. Medline

10. Moosa MR, Meyers AM, Gottlich E, Naicker S. An effective approach to chronic kidney disease in South Africa. S Afr Med J. 2016;106(2):156-159. CrossRef. Medline

11. Stauffer ME, Fan T. Prevalence of anemia in chronic kidney disease in the United States. PLoS One. 2014;9(1):e84943. CrossRef. Medline

12. Pyram R, Kansara A, Banerii MA, Loney-Hutchinson L. Chronic kidney disease and diabetes. Maturitas. 2012;71(2):94-103. CrossRef. Medline

13. Lau BCV, Ong KY, Yap CW, Vathsala A, How P. Predictors of anemia in a multiethnic chronic kidney disease population: a case-control study. SpringerPlus. 2015;4:233. CrossRef. Medline

14. Oluyombo R, Ayodele OE, Akinwusi PO, et al. A community study of the prevalence, risk factors and pattern of chronic kidney disease in Osun State, South West Nigeria. West Afr J Med. 2013;32(2):85-92. Medline

15. Janmohamed MN, Kallurya SE, Mueller A, Kabangila R, Smart LR, Downs JA, Peck RN. Prevalence of chronic kidney disease in diabetic adult out-patients in Tanzania. BMC Nephrol. 2013;14:183. CrossRef. Medline

16. Stanifer JW, Maro V, Egger J, et al. The epidemiology of chronic kidney disease in Northern Tanzania: a population-based survey. PLoS One. 2015;10(4):e0124506. CrossRef. Medline

17. Peck RN, Green E, Mtabaji J, Majinge C, Smart LR, Downs JA, Fitzgerald DW. Hypertension-related diseases as a common cause of hospital mortality in Tanzania: a 3-year prospective study. J Hypertens. 2013;31(9):1806-1811. CrossRef. Medline

18. Coresh J, Astor BC, Greene T, Eknoyan G, Levey AS. Prevalence of chronic kidney disease and decreased kidney function in the adult US population: third national health and nutrition examination survey. Am J Kidney Dis. 2003;41 (1):1-12. CrossRef. Medline

19. Okafor U, Ahmed S, Arigbodi O, Idogun S, Unuigbe El. Screening for kidney disease in an oil producing community in Nigeria: a pilot study. Saudi J Kidney Dis Transpl. 2016;27(4):781-786. CrossRef. Medline

20. Hill NR, Fatoba ST, Oke JL, Hirst JA, O'Callaghan CA, Lasserson DS, Hobbs FD. Global prevalence of chronic kidney disease - a systematic review and metaanalysis. PLoS One. 2016;1 1(7):e0158765. CrossRef. Medline

21. National Clinical Guideline Centre (UK). Anaemia Management in Chronic Kidney Disease, Partial Update 2015. NICE Guideline, No. 8. London: Royal College of Physicians; 2015.

\section{Peer Reviewed}

Competing Interests: None declared.

Received: 31 Oct 2016; Accepted: 19 Dec 2017

Cite this article as: Meremo AJ, Masalu MB, Sabi I, Ngilangwa DP, Kapinga J, Tagalile $\mathrm{R}$, et al. Prevalence and Risk Factors Associated With Chronic Kidney Disease Among Patients Presenting at a Haemodialysis Unit in Dodoma, Tanzania. East African Health Res J. 2018;2(1):53-57. https://doi.org/10.24248/EAHRJ-D-16-00367

(C) Meremo et al. This is an open-access article distributed under the terms of the Creative Commons Attribution License, which permits unrestricted use, distribution, and reproduction in any medium, provided the original author and source are properly cited. To view a copy of the license, visit http://creativecommons.org/licenses/by/ 4.0/. When linking to this article, please use the following permanent link: https:// doi.org/10.24248/EAHRJ-D-16-00367 